\title{
The postoperative peak number of leukocytes after hepatectomy is a significant prognostic factor for cholangiocarcinoma
}

\author{
GO SHINKE $^{1}$, DAISAKU YAMADA ${ }^{1,2}$, HIDETOSHI EGUCHI ${ }^{1}$, YOSHIFUMI IWAGAMI ${ }^{1}$, HIROFUMI AKITA ${ }^{1}$, \\ TADAFUMI ASAOKA ${ }^{1}$, TAKEHIRO NODA ${ }^{1}$, KUNIHITO GOTOH $^{1}$, SHOGO KOBAYASHI $^{1}$, YUTAKA TAKEDA ${ }^{1,3}$, \\ MASAHIRO TANEMURA $^{1,4}$, YUICHIRO DOKI ${ }^{1}$ and MASAKI MORI ${ }^{1}$ \\ ${ }^{1}$ Department of Gastroenterological Surgery, Graduate School of Medicine, Osaka University, Suita, Osaka 565-0871; \\ ${ }^{2}$ Department of Gastroenterological Surgery, Osaka International Cancer Institute, Osaka 541-8567; \\ ${ }^{3}$ Department of Surgery, Kansai Rosai Hospital, Amagasaki, Hyogo 660-8511; \\ ${ }^{4}$ Department of Surgery, Osaka Police Hospital, Osaka 558-8558, Japan
}

Received October 24, 2018; Accepted February 14, 2019

DOI: $10.3892 / \mathrm{mco} .2019 .1827$

\begin{abstract}
Cholangiocarcinoma (CCA) is a lethal disease. A new predictive factor to identify patients suitable for adjuvant chemotherapy is needed. The relationship between the long-term prognosis and the perioperative immune responses in patients with CCA remains unclear. We therefore investigated the clinical impact of perioperative immune responses on the long-term prognosis in patients receiving hepatectomy for CCA. We investigated 81 patients who underwent hepatectomy between February 2000 and October 2012: 57 intra-hepatic CCA (iCCA) patients and 24 extra-hepatic CCA (eCCA) patients. We checked the postoperative level of C-reactive protein and the numbers of leukocytes. A multivariate analysis of the clinicopathological factors identified 2 significant risk factors for the overall survival: The postoperative maximum number of leukocytes (PNL) among patient factors $(\mathrm{P}=0.0406)$ and the TNM-stage among tumor factors $(\mathrm{P}=0.0059)$. On evaluating the distribution of each kind of leukocyte with a multivariate analysis, both the postoperative maximum number of neutrophils (PNN) and the postoperative maximum number of eosinophils (PNE) were detected as significant factors among leukocytes (PNN/PNE, $\mathrm{P}=0.0367 / 0.0083$ ). In conclusion, the PNL after hepatectomy was significantly associated with the long-term prognosis in patients with CCA. Changes in the numbers of leukocytes after hepatectomy may be a marker on treatment for CCA.
\end{abstract}

\section{Introduction}

Cholangiocarcinoma (CCA) is a fatal neoplasm with a poor prognosis. Despite developments in its detection and treatment,

Correspondence to: Dr Hidetoshi Eguchi, Department of Gastroenterological Surgery, Graduate School of Medicine, Osaka University, 2-2 Yamadaoka, Suita, Osaka 565-0871, Japan

E-mail: heguchi@gesurg.med.osaka-u.ac.jp

Key words: cholangiocarcinoma, eosinophil, hepatectomy, neutrophil, leucocyte only approximately $5-15 \%$ of CCA patients survive for 5 years after the diagnosis (1-4). Surgery is the only curative treatment for CCA; however, the overall survival (OS) is not satisfactory, with a 5-year OS of 40\% in patients treated with surgery (5-7). To improve the OS, several adjuvant chemotherapies after surgery for CCA have been performed. However, despite a number of studies demonstrating the potential efficacy of adjuvant chemotherapies (8-10), there is no secure evidence on which to highly recommend adjuvant chemotherapy be administered for CCA. One reason for this is that patients are unlikely to tolerate chemotherapy after surgery, especially after hepatectomy. We therefore need to identify those patients who will receive a substantial clinical benefit from adjuvant chemotherapy.

Among preoperative systemic immunological and inflammatory clinical variables, the neutrophil-to-lymphocyte ratio (NLR), platelet-lymphocyte ratio (PLR) and prognostic nutritional index (PNI) have been reported as predictors of the therapeutic outcome in cancer, including CCA (11-13). The postoperative immune response was also reported as a risk factor of the prognosis among patients with other cancers (14-16). For hepatocellular carcinoma after hepatectomy, it was reported that the perioperative change in the leukocyte number and levels of postoperative C-reactive protein (CRP) were associated with the survival $(17,18)$. However, the relationship between the long-term prognosis and the perioperative immune responses in patients with CCA has remained unclear.

In this study, we investigated the clinical impact of the perioperative immune response on the long-term prognosis in patients receiving hepatectomy for CCA.

\section{Materials and methods}

Rules for CCA used in the present study. In this study, we used the 6th edition of the general rules for clinical and pathological studies on cancer of the biliary tract for extra-hepatic CCA (eCCA) and the 6th edition of the general rules for the clinical and pathological study of primary liver cancer for intra-hepatic CCA (iCCA) $(19,20)$. Because R0 resection in the 
6th edition of the general rules for clinical and pathological studies on cancer of the biliary tract are equivalent to Cur A and $\mathrm{B}$ in the 6th edition of the general rules for the clinical and pathological study of primary liver cancer, we defined Cur A and $\mathrm{B}$ as $\mathrm{R} 0$ in this article.

Patients. Between February 2000 and October 2012, 109 patients diagnosed with iCCA or eCCA underwent R0 resection in the Department of Gastroenterological Surgery at Osaka University Hospital. After a routine examination, including a blood test, computed tomography, endoscopic retrograde cholangiography and/or percutaneous transhepatic cholangiography, 81 patients (57 iCCA patients and 24 eCCA patients) underwent hepatectomy.

In this study, written informed consent to receive perioperative management was obtained from all of the patients.

The criteria used for surgery were based on three factors; the preoperative liver function, the cut margin and the size of the remnant liver. In brief, the cutting line of the biliary duct should be $5 \mathrm{~mm}$ away from the CCA, and the estimated remnant liver volume should be $>30 \%$ of the total liver volume with a normal liver function. If needed, percutaneous transhepatic portal embolization was performed before surgery.

Adjuvant chemotherapy and follow-up. Several kinds of adjuvant chemotherapies following hepatectomy were performed for some patients in this cohort as clinical trials in 2011-2012 $(3,9)$. Patients with major hepatectomy were assigned to KHBO 1003, 'Phase I study of adjuvant gemcitabine or S-1 in patients with biliary tract cancers undergoing major hepatectomy' (Clinical-Trials.gov ID NCT01291615; UMIN ID 000004682), and were treated with GEM or S-1 chemotherapy. Patients with small hepatectomy were assigned to KHBO 1004, 'A Phase I study of adjuvant chemotherapy with gemcitabine plus cisplatin in patients with biliary tract cancer undergoing curative resection without major hepatectomy' (Clinical-Trials.gov ID NCT01297998; UMIN ID 000004622), and were treated with GEM plus cisplatin therapy. The median follow-up period of all patients was $50.6 \pm 38.1$ months. Patients received regular follow-up with abdominal computed tomography and measurement of the serum CEA and CA19-9 levels every three months for the first two years and every six months thereafter. The last follow-up date of this study was November 2017.

Treatment for recurrence. Almost all of patients with recurrence were first treated by gemcitabine (GEM). The chemotherapy comprised oral 5-fulorouracil (5FU) and/or tegafur or the combination of 5FU, adriamycin, and cisplatin until June 2006, when GEM for CCA was approved in Japan.

Evaluations of the clinicopathological features. We collected all information related to three types of factors: patient factors, tumor factors and treatment factors. Regarding patient factors, we evaluated each patient's condition from multiple perspectives. Because several reports have suggested that the nutritional state or inflammation condition affects the prognosis of CCA, we evaluated whether or not these factors were associated with the long-term prognosis. The nutritional state of the patients before surgery was evaluated with Onodera's
PNI. The inflammation-associated status at the same time point was also evaluated with two scores: the NLR and the PLR. These statuses were evaluated based on blood tests within one week before surgery. We checked the postoperative first peak of the level of CRP and the numbers of each kind of leukocyte (neutrophils, lymphocytes, eosinophils, monocytes and basophils). Each kind of leukocytes reached the peak at the various date after surgery; the median date of each kind of leukocytes (leukocytes/neutrophils/lymphocytes/eosinophils/monocytes/basophils) was 2nd/1st/13th/14th/6th/11th date, respectively. Regarding to neutrophils, they usually reached the peak around the same time as leukocytes, but the peak of eosinophils was usually delayed several days from the peak of leukocytes.

Regarding tumor factors, we collected all tumor information relevant to the pathological diagnosis. The TNM and stage of tumors were classified by different rules between eCCA and iCCA. The 6th edition of the general rules for clinical and pathological studies on cancer of the biliary tract was used for eCCA, and the 6th edition of the general rules for the clinical and pathological study of primary liver cancer was used for iCCA. The levels of the tumor markers CEA and CA19-9 were evaluated the day before surgery. Treatment factors consisted of information concerning the surgery type, the complications following surgery and the presence of adjuvant therapy. All morbidities were judged as clinically relevant postoperative complications when a surgical or interventional radiology approach was required (Table I).

Statistical analyses. All data are expressed as the mean \pm standard deviation. The chi-squared test and Fisher's exact test were used to compare categorical variables, when appropriate. The Kaplan-Meier analysis and the log-rank test were used to construct the survival curve and to evaluate differences for the univariate analysis. A multivariate analysis of the detected factors was performed with a Cox regression analysis. All analyses were conducted with the JMP 13 software program (SAS Institute, Cary, NC, USA). Statistical significance was defined as a P-value of 0.05 .

Ethical guidelines followed in this study. This study was conducted in accordance with the Declaration of Helsinki. This study was performed at Osaka University Hospital, Japan, and approved by the local ethics committee (no. 18261).

\section{Results}

The peak number of leukocytes after hepatectomy was an individual significant risk factor for the OS in CCA patients. Eighty-one patients of CCA received liver resection; 57 of them had intrahepatic CCA, and 24 had perihilar CCA (Table I). The univariate analysis detected several risk factors for the OS in CCA patients receiving hepatectomy, including 2 among the patient factors (the PLR $(\mathrm{P}=0.0251)$ and the postoperative maximum number of leukocytes (PNL, $\mathrm{P}=0.0111)$ ); 6 among the tumor features [TNM classification $(\mathrm{T} / \mathrm{N} / \mathrm{M}, \mathrm{P}=0.0091 / 0.0003 / 0.0002)$, historical vascular invasion $(\mathrm{P}<0.0001)$, staging $(\mathrm{P}=0.0030)$ and level of $\mathrm{CA} 19-9$ $(\mathrm{P}=0.0383)]$; and 4 among the treatment features (operation time $(\mathrm{P}=0.0113)$, blood loss $(\mathrm{P}=0.0372)$, morbidity $(\mathrm{P}=0.0040)$ 
Table I. Clinicopathological features in 81 CCA patients by each factor type.

\begin{tabular}{|c|c|}
\hline Variable & $\mathrm{n}=81$ \\
\hline \multicolumn{2}{|l|}{ Patient factors } \\
\hline Age (years) & $63.7 \pm 10.9$ \\
\hline Sex (male:female) & $52: 29$ \\
\hline Jaundice (present:absent) & $6: 75$ \\
\hline PNI & $44.1 \pm 4.8$ \\
\hline NLR & $2.8 \pm 1.5$ \\
\hline PLR & $174.6 \pm 89.5$ \\
\hline Postoperative maximum number of leukocytes $(/ \mu 1)$ & $12182 \pm 3748$ \\
\hline Postoperative maximum number of neutrophils $(/ \mu \mathrm{l})$ & $9986 \pm 3730$ \\
\hline Postoperative maximum number of lymphocytes $(/ \mu 1)$ & $1542 \pm 529$ \\
\hline Postoperative maximum number of eosinophils $(/ \mu 1)$ & $466 \pm 419$ \\
\hline Postoperative maximum number of monocytes $(/ \mu 1)$ & $879 \pm 316$ \\
\hline Postoperative maximum number of basophils $(/ \mu \mathrm{l})$ & $106 \pm 364$ \\
\hline Postoperative peak value of CRP (mg/dl) & $10.2 \pm 4.2$ \\
\hline \multicolumn{2}{|l|}{ Tumor factors } \\
\hline Tumor type (intrahepatic CCA:perihilar CCA) & $57: 24$ \\
\hline Differentiation (tub1:tub2:por:muc:small cell:unknown) & $8: 51: 12: 6: 1: 1: 2$ \\
\hline $\mathrm{pT}^{\mathrm{a}}(1: 2: 3: 4)$ & $7: 38: 27: 8$ \\
\hline Historical vascular invasion (present absent) & $35: 44$ \\
\hline Tumor size $(\mathrm{cm})$ & $4.1 \pm 2.7$ \\
\hline $\mathrm{pN}^{\mathrm{a}}(1: 0)$ & $24: 56$ \\
\hline $\mathrm{pMN}^{\mathrm{a}}(1: 0)$ & $1: 80$ \\
\hline pStageNa(I:II:III:IV) & $7: 33: 19: 21$ \\
\hline $\mathrm{CEA}(>5:<5 \mathrm{ng} / \mathrm{ml})$ & $10: 71$ \\
\hline CA19-9 (>37:<37 U/ml) & $36: 45$ \\
\hline \multicolumn{2}{|l|}{ Treatment factors } \\
\hline Adjuvant therapy (yes:no) & 29:52 \\
\hline Treatment after recurrence with gemcitabine (yes:no:unknown:no recurrence) & $24: 36: 2: 19$ \\
\hline $\begin{array}{l}\text { Operative method (HPD: trisectionectomy:hemihepatectomy: } \\
\text { segmentectomy:subseqmentectomy:partial hepatectomy) }\end{array}$ & $1: 8: 49: 5: 2: 16$ \\
\hline Operation time (min) & $536.8 \pm 202.2$ \\
\hline Blood loss (ml) & $1451.1 \pm 1148.8$ \\
\hline Morbidity (present:absent) & $14: 67$ \\
\hline Resected liver weight (g) & $420.4 \pm 316.1$ \\
\hline
\end{tabular}

CCA, cholangiocarcinoma; HPD, hepatopancreatoduodenectomy; CRP, C-reactive protein; PNI, prognostic nutritional index, NLR, neutrophil-to-lymphocyte ratio; PLR, platelet-to-lymphocyte ratio; tub1, well differentiated type; tub2, moderately differentiated type; por, poorly

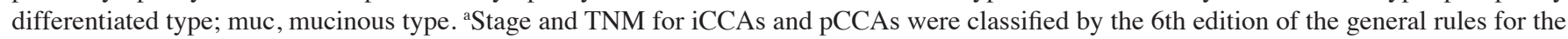
clinical and pathological study of primary liver cancer and the 6th edition of general rules for clinical and pathological studies on cancer of the biliary tract, respectively.

and resected liver weight $(\mathrm{P}=0.0103)]$. A multivariate analysis of those risk factors revealed 2 significant risk factors for the OS: The PNL among patient factors $(\mathrm{P}=0.0406)$ and the TNM-stage among tumor factors $(\mathrm{P}=0.0059)$. There were no significant risk factors for the OS among treatment factors (Table II).

To clarify which kinds of leukocytes were significantly associated with the OS, we evaluated the distribution of each kind among neutrophils, lymphocytes, eosinophils, monocytes and basophils. A multivariate analysis was performed, and both the postoperative maximum number of neutrophils (PNN) and postoperative maximum number of eosinophils (PNE) were detected as significant factors among leukocytes (PNN/PNE, $\mathrm{P}=0.0367 / 0.0083$, Table III).

$P N N$. We divided patients into a high-neutrophil group (high-PNN group, $\mathrm{n}=40$ ) and a Lowl-neutrophil group (low-PNN group, $\mathrm{n}=41)$ based on the median PNN $(9807 / \mu 1)$. The high-PNN group showed a poorer prognosis than the low-PNN group with regard to the OS $(\mathrm{P}=0.0406)$. To assess the influence of the increase in neutrophils after hepatectomy, a sub-analysis for the OS was performed. The high-PNN group 
Table II. Results of univariate and multivariate analyses for the OS.

\begin{tabular}{|c|c|c|c|c|c|}
\hline \multirow[b]{2}{*}{ Variable } & \multirow{2}{*}{$\begin{array}{c}\text { MST } \\
\text { (months) }\end{array}$} & \multirow{2}{*}{$\begin{array}{c}\text { Univariate } \\
\text { analysis } \\
\text { P-value }\end{array}$} & \multicolumn{3}{|c|}{ Multivariate analysis } \\
\hline & & & HR & $(95 \% \mathrm{CI})$ & P-value \\
\hline \multicolumn{6}{|l|}{ Patient factors } \\
\hline Age $(<65: \geq 65$ years $)$ & 39.4:69.2 & 0.3968 & & & \\
\hline Sex (male:female) & 69.9:43.1 & 0.2617 & & & \\
\hline Jaundice (present:absent) & $56.5: 51.8$ & 0.9873 & & & \\
\hline PNI $(\leq 45:>45)$ & $52.2: 51.8$ & 0.8540 & & & \\
\hline $\operatorname{NLR}(\leq 2.5:>2.5)$ & $69.2: 39.4$ & 0.1215 & & & \\
\hline $\operatorname{PLR}(\leq 150:>150)$ & 74.8:43.1 & 0.0251 & 0.59 & $(0.32-1.08)$ & 0.0906 \\
\hline $\begin{array}{l}\text { Postoperative maximum number of leukocytes } \\
(\leq 11580:>11580 / \mu 1)\end{array}$ & $74.8: 32.7$ & 0.0111 & 0.54 & $(0.29-0.97)$ & 0.0406 \\
\hline $\begin{array}{l}\text { Postoperative peak value of CRP } \\
(\leq 9.7:>9.7 \mathrm{mg} / \mathrm{dl})\end{array}$ & $59.2: 43.1$ & 0.5203 & & & \\
\hline \multicolumn{6}{|l|}{ Tumor factors } \\
\hline Tumor type (intrahepatic CCA:perihilar CCA) & $53.8: 43.7$ & 0.1210 & & & \\
\hline Differentiation (tub1, tub2: others) & 47.7:- & 0.1818 & & & \\
\hline $\mathrm{pT}^{\mathrm{a}}(1,2: 3,4)$ & $70.5: 30.3$ & 0.0091 & & & N.A. \\
\hline Historical vascular invasion (present: absent) & 29.9:- & $<0.0001$ & & & N.A. \\
\hline Tumor size $(\leq 2:>2 \mathrm{~cm})$ & 69.9:51.5 & 0.5559 & & & \\
\hline $\mathrm{pN}^{\mathrm{a}}(0: 1)$ & 69.9:18.8 & 0.0003 & & & N.A. \\
\hline $\mathrm{pM}^{\mathrm{a}}(1: 0)$ & $6.4: 51.8$ & 0.0002 & & & N.A. \\
\hline pStage $^{\mathrm{a}}(\mathrm{I}, \mathrm{II}: \mathrm{III}, \mathrm{IV})$ & 78.3:29.9 & 0.0030 & 0.44 & $(0.24-0.79)$ & 0.0059 \\
\hline $\mathrm{CEA}(\leq 5:>5 \mathrm{ng} / \mathrm{ml})$ & $52.2: 27.2$ & 0.0688 & & & \\
\hline CA19-9 ( $\leq 37:>37 \mathrm{U} / \mathrm{ml})$ & $69.2: 30.8$ & 0.0383 & 0.60 & $(0.33-1.08)$ & 0.0888 \\
\hline \multicolumn{6}{|l|}{ Treatment factors } \\
\hline Adjuvant therapy (yes:no) & $39.4: 59.2$ & 0.9716 & & & \\
\hline Treatment after recurrence with gemcitabine (yes:no) & $43.7: 27.9$ & 0.3503 & & & \\
\hline Operative method of hepatectomy (major:minor) & 47.7:- & 0.1265 & & & \\
\hline Operation time $(\leq 545:>545 \mathrm{~min})$ & $74.8: 27.4$ & 0.0113 & 0.66 & $(0.32-1.29)$ & 0.2238 \\
\hline Blood loss $(<1,000: \geq 1,000 \mathrm{ml})$ & $70.5: 30.3$ & 0.0372 & 0.92 & $(0.44-1.89)$ & 0.8249 \\
\hline Morbidity (present:absent) & $20.4: 59.2$ & 0.0040 & 1.86 & $(0.82-3.97)$ & 0.1346 \\
\hline Resected liver weight $(\leq 340:>340 \mathrm{~g})$ & $-: 39.4$ & 0.0103 & 0.64 & $(0.30-1.34)$ & 0.2365 \\
\hline
\end{tabular}

OS, overall survival; MST, median survival time; N.A., not available; PNI, prognostic nutritional index; NLR, neutrophil-to-lymphocyte ratio; PLR, platelet-to-lymphocyte ratio; CRP, C-reactive protein; CCA, cholangiocarcinoma; tub1, well differentiated type; tub2, moderately differentiated type; major hepatectomy, $>3$ segments; minor hepatectomy, $\leq 3$ segments. P-value $<0.05$ was considered statistically significant.

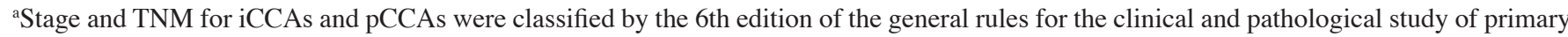
liver cancer and the 6th edition of general rules for clinical and pathological studies on cancer of the biliary tract, respectively.

showed a poorer prognosis than the low-PNN group $(\mathrm{P}=0.0318)$ in the survival time after recurrence (SAR). However, no significant difference in the disease-free survival (DFS) was noted between the groups $(\mathrm{P}=0.8809)$ (Fig. 1A).

To investigate the factors associated with the PNN, we compared the clinicopathological factors between the two groups. The comparison revealed significant differences in three factors: the level of CA19-9, CCA tumor type and the PLR. The high-PNN group contained more patients showing a higher preoperative CA19-9 level $(\mathrm{P}=0.0259)$ and high PLR $(\mathrm{P}=0.0018)$. In addition, the number of neutrophils in the serum was higher in iCCA patients than in eCCA patients after hepatectomy $(\mathrm{P}=0.0035)$ (Table IV).
PNE. When patients were divided into a high-eosinophil group (high-PNE group, $\mathrm{n}=40$ ) and a low-eosinophil group (low-PNE group, $\mathrm{n}=41$ ) based on the median PNE (356/ $\mu \mathrm{l})$, the low-PNE group showed a poorer prognosis with regard to the OS $(\mathrm{P}=0.0111)$ and the SAR $(\mathrm{P}=0.0086)$ (Fig. 1B). However, there was no significant difference in the DFS between the groups $(\mathrm{P}=0.2334)$ (Fig. 1B).

We investigated the factors associated with the PNE and determined that only the preoperative serum level of CA19-9 was associated with the PNE $(\mathrm{P}=0.0445)$ (Table V).

The rule of peak number of leukocytes after hepatectomy for the SAR in CCA patients. Because both PNN and PNE 
Table III. Results of a multivariate analysis for the OS in leukocytes.

\begin{tabular}{|c|c|c|c|}
\hline \multirow[b]{2}{*}{ Variable } & \multicolumn{3}{|c|}{ Multivariate analysis } \\
\hline & HR & $(95 \% \mathrm{CI})$ & P-value \\
\hline Postoperative maximum number of leukocytes $(\leq 11580:>11580 / \mu \mathrm{l})$ & & & N.A. \\
\hline Postoperative maximum number of neutrophils $(\leq 9807:>9807 / \mu 1)$ & 0.53 & $(0.28-0.96)$ & 0.0367 \\
\hline Postoperative maximum number of lymphocytes $(\leq 1513:>1513 / \mu 1)$ & 1.06 & $(0.56-2.01)$ & 0.8549 \\
\hline Postoperative maximum number of eosinophils $(\leq 356:>356 / \mu 1)$ & 2.20 & $(1.22-4.04)$ & 0.0083 \\
\hline Postoperative maximum number of monocytes $(\leq 815:>815 / \mu 1)$ & 0.95 & $(0.52-1.74)$ & 0.8752 \\
\hline Postoperative maximum number of basophils $(\leq 58:>58 / \mu 1)$ & 0.94 & $(0.50-1.77)$ & 0.8527 \\
\hline
\end{tabular}

OS, overall survival; N.A., not available. P-value $<0.05$ was considered statistically significant.

Table IV. Results of a univariate analysis of patient characteristics and postoperative peak number of neutrophils.

\begin{tabular}{|c|c|c|c|c|}
\hline Variable & $\mathrm{n}$ & $\begin{array}{c}\text { High } \\
\text { neutrophils } \\
(\mathrm{n}=40)\end{array}$ & $\begin{array}{l}\text { Low } \\
\text { neutrophils } \\
(\mathrm{n}=41)\end{array}$ & P-value \\
\hline Age $(<65: \geq 65$ years $)$ & $37: 44$ & $19: 21$ & $18: 23$ & 0.8249 \\
\hline Sex (male:female) & $52: 29$ & $24: 16$ & $28: 13$ & 0.4919 \\
\hline $\mathrm{CEA}(\leq 5:>5 \mathrm{ng} / \mathrm{ml})$ & $71: 10$ & $34: 6$ & $37: 4$ & 0.5187 \\
\hline CA19-9 ( $\leq 37:>37 \mathrm{U} / \mathrm{ml})$ & $45: 36$ & $17: 23$ & $28: 13$ & 0.0259 \\
\hline Jaundice (present:absent) & $6: 75$ & $5: 35$ & $1: 40$ & 0.1088 \\
\hline Adjuvant therapy (yes:no) & 29:52 & $14: 26$ & $15: 26$ & 0.1394 \\
\hline Tumor type (intrahepatic CCA:perihilar CCA) & $57: 24$ & $22: 18$ & $35: 6$ & 0.0035 \\
\hline Differentiation (tub1, tub2:others) & $59: 20$ & 27:11 & $32: 9$ & 0.6059 \\
\hline Operation time $(\leq 545:>545 \mathrm{~min})$ & 41:39 & $16: 23$ & $25: 16$ & 0.1168 \\
\hline Blood loss $(<1,000: \geq 1,000 \mathrm{ml})$ & $36: 45$ & $18: 22$ & $18: 23$ & 1.0000 \\
\hline Morbidity (present:absent) & $14: 67$ & $10: 30$ & $4: 37$ & 0.0843 \\
\hline Resected liver weight ( $\leq 340:>340 \mathrm{~g})$ & $37: 39$ & $15: 23$ & $22: 16$ & 0.1681 \\
\hline Operative method of hepatectomy (major:minor) & $58: 23$ & $32: 8$ & $26: 15$ & 0.1394 \\
\hline $\mathrm{pT}^{\mathrm{a}}(1,2: 3,4)$ & $45: 35$ & $22: 17$ & $23: 18$ & 1.0000 \\
\hline Historical vascular invasion (present:absent) & $35: 44$ & $21: 17$ & $32: 9$ & 0.6059 \\
\hline Tumor size $(\leq 2:>2 \mathrm{~cm})$ & 18:62 & $11: 28$ & $7: 34$ & 0.2890 \\
\hline $\mathrm{pN}^{\mathrm{a}}(0: 1)$ & $56: 24$ & $26: 13$ & $30: 11$ & 0.6276 \\
\hline $\mathrm{pM}^{\mathrm{a}}(1: 0)$ & $1: 80$ & $1: 39$ & $0: 41$ & 0.4938 \\
\hline pStage (I, II:III, IV) & $40: 40$ & $18: 21$ & $22: 19$ & 0.6549 \\
\hline PNI $(\leq 45:>45)$ & $49: 32$ & $27: 13$ & $22: 19$ & 0.2576 \\
\hline $\operatorname{NLR}(\leq 2.5:>2.5)$ & $40: 41$ & $18: 22$ & $22: 19$ & 0.5077 \\
\hline PLR ( $\leq 150:>150)$ & $39: 42$ & $12: 28$ & $27: 14$ & 0.0018 \\
\hline Postoperative maximum number of lymphocytes $(\leq 1513:>1513 / \mu 1)$ & $41: 40$ & $18: 22$ & $23: 18$ & 0.3771 \\
\hline Postoperative maximum number of eosinophils $(\leq 356:>356 / \mu 1)$ & $41: 40$ & $18: 22$ & $23: 18$ & 0.3771 \\
\hline Postoperative maximum number of monocytes $(\leq 815:>815 / \mu 1)$ & 41:40 & $17: 23$ & $24: 17$ & 0.1848 \\
\hline Postoperative maximum number of basophils $(\leq 58:>58 / \mu 1)$ & $41: 40$ & $16: 24$ & $25: 16$ & 0.0766 \\
\hline Postoperative peak value of CRP $(\leq 9.7:>9.7 \mathrm{mg} / \mathrm{dl})$ & 41:40 & $19: 21$ & $22: 19$ & 0.6590 \\
\hline
\end{tabular}

OS, overall survival; CCA, cholangiocarcinoma; tub1, well differentiated type; tub2, moderately differentiated type; PNI, prognostic nutritional index; NLR, neutrophil-to-lymphocyte ratio; PLR, platelet-to-lymphocyte ratio; CRP, C-reactive protein; major hepatectomy, $>3$ segments;

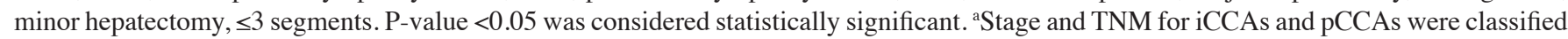
by the 6th edition of the general rules for the clinical and pathological study of primary liver cancer and the 6th edition of general rules for clinical and pathological studies on cancer of the biliary tract, respectively. 
A
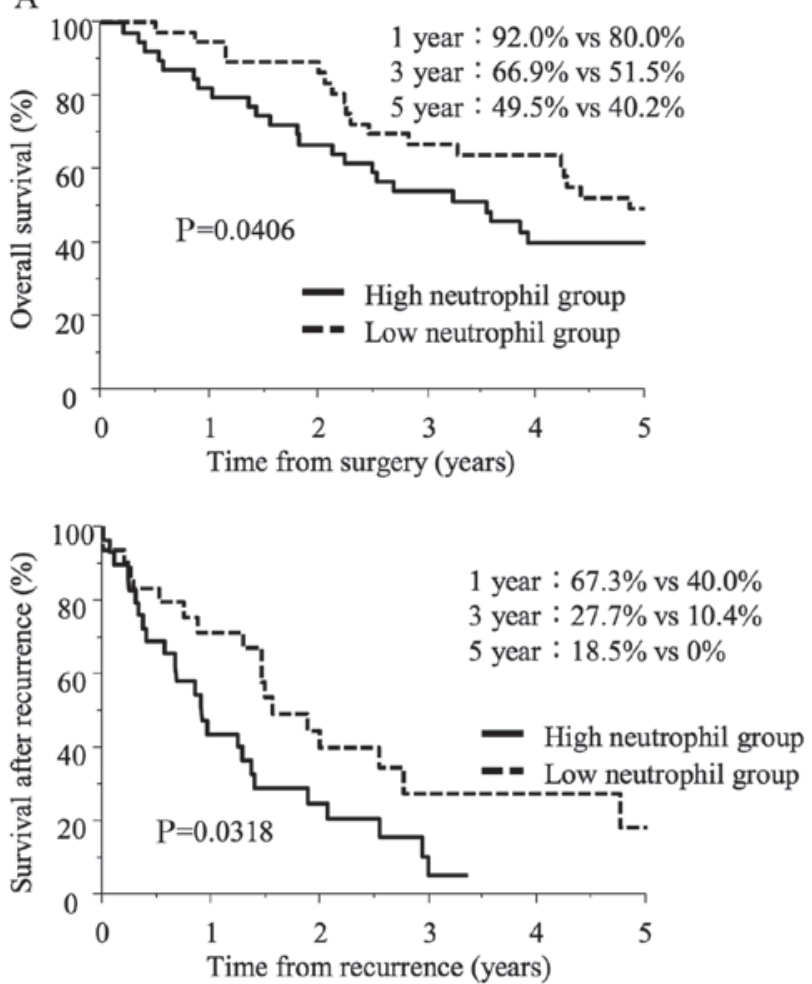

B $\quad 1$ year : $94.9 \%$ vs $79.7 \%$
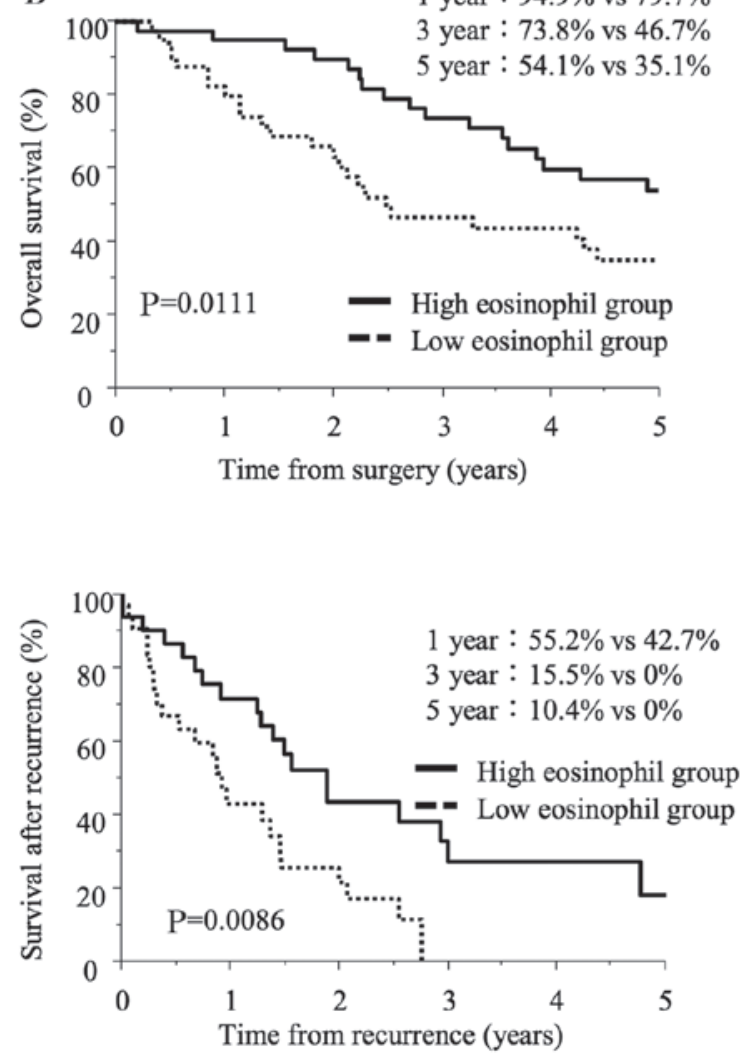

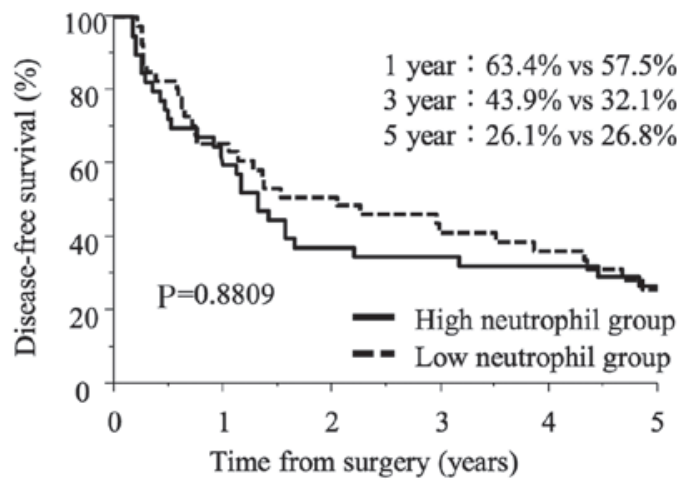

1 year : $63.4 \%$ vs $57.5 \%$

. $33.9 \%$ vs $32.1 \%$

5 year : $26.1 \%$ vs $26.8 \%$

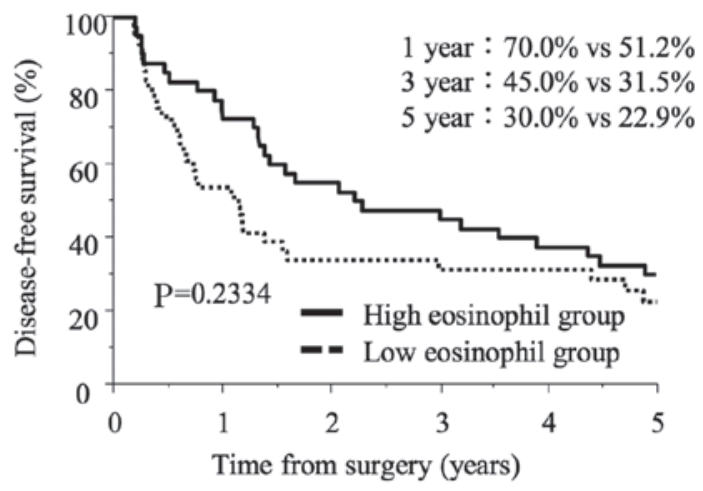

Figure 1. The long-term prognosis of patients after hepatectomy for cholangiocarcinoma (CCA). (A) The overall survival (OS, upper left), disease-free survival (DFS, upper right) and survival after recurrence (SAR, lower left) curves after surgery for 81 patients with CCA. Patients were divided into two groups according to the median postoperative peak number of neutrophils. The median OS in the high-neutrophil group $(\mathrm{n}=40)$ and low-neutrophil group $(\mathrm{n}=41)$ was 43.1 and 59.2 months, respectively; $\mathrm{P}=0.0406$. The median DFS in the high-neutrophil group and low-neutrophil group was 16.1 and 25 . months, respectively; $\mathrm{P}=0.8809$. The median SAR in the high-neutrophil group and low-neutrophil group was 11.0 and 18.8 months, respectively; 0.0318 . (B) The OS (upper left), DFS (upper right) and SAR (lower left) curves after surgery for 81 patients with CCA. Patients were divided into two groups according to the median postoperative peak number of eosinophils. The median OS in the high-eosinophil group $(n=40)$ and low-eosinophil group ( $n=41)$ was 74.8 and 30.3 months, respectively; $\mathrm{P}=0.0111$. The median DFS in the high-eosinophil group and low-eosinophil group was 27.3 and 13.8 months, respectively; $\mathrm{P}=0.2334$. The median SAR in the high-eosinophil group and low-eosinophil group was 22.8 and 11.0 months, respectively; $\mathrm{P}=0.0086$. 
Table V. Results of a univariate analysis of patient characteristics and postoperative peak number of eosinophils.

\begin{tabular}{|c|c|c|c|c|}
\hline Variable & $\mathrm{n}$ & $\begin{array}{c}\text { High } \\
\text { eosinophils } \\
(n=40)\end{array}$ & $\begin{array}{c}\text { Low } \\
\text { eosinophils } \\
(n=41)\end{array}$ & P-value \\
\hline Age $(<65: \geq 65$ years $)$ & $37: 44$ & $17: 23$ & $20: 21$ & 0.6575 \\
\hline Sex (male:female) & $52: 29$ & $27: 13$ & $25: 16$ & 0.6445 \\
\hline $\mathrm{CEA}(\leq 5:>5 \mathrm{ng} / \mathrm{ml})$ & $71: 10$ & $34: 6$ & $37: 4$ & 0.5187 \\
\hline CA19-9 ( $\leq 37:>37 \mathrm{U} / \mathrm{ml})$ & $45: 36$ & $27: 13$ & $18: 23$ & 0.0445 \\
\hline Jaundice (present:absent) & $6: 75$ & $4: 36$ & $2: 39$ & 0.4321 \\
\hline Adjuvant therapy (yes:no) & $29: 52$ & $16: 24$ & $13: 28$ & 0.4919 \\
\hline Tumor type (intrahepatic CCA:perihilar CCA) & $57: 24$ & 28:12 & $29: 12$ & 1.0000 \\
\hline Differentiation (tub1, tub2:others) & $59: 20$ & $32: 8$ & $27: 12$ & 0.3095 \\
\hline Operation time $(\leq 545:>545 \mathrm{~min})$ & $41: 39$ & $23: 17$ & $18: 22$ & 0.3711 \\
\hline Blood loss $(<1,000: \geq 1,000 \mathrm{ml})$ & $36: 45$ & 20:20 & $16: 25$ & 0.3749 \\
\hline Morbidity (present:absent) & $14: 67$ & $7: 33$ & $7: 34$ & 1.0000 \\
\hline Resected liver weight $(\leq 340:>340 \mathrm{~g})$ & $37: 39$ & $22: 17$ & $15: 22$ & 0.1786 \\
\hline Operative method of hepatectomy (major:minor) & $58: 23$ & $27: 13$ & $31: 10$ & 0.4670 \\
\hline $\mathrm{pT}^{\mathrm{a}}(1,2: 3,4)$ & $45: 35$ & $26: 14$ & $19: 21$ & 0.1759 \\
\hline Historical vascular invasion (present:absent) & $35: 44$ & $16: 24$ & $19: 20$ & 0.5005 \\
\hline Tumor size $(\leq 2:>2 \mathrm{~cm})$ & $18: 62$ & $9: 31$ & $9: 31$ & 1.0000 \\
\hline $\mathrm{pN}^{\mathrm{a}}(0: 1)$ & $56: 24$ & $32: 8$ & $24: 16$ & 0.0866 \\
\hline $\mathrm{pM}^{\mathrm{a}}(1: 0)$ & $1: 80$ & $0: 40$ & $1: 40$ & 1.0000 \\
\hline pStage $^{\mathrm{a}}(\mathrm{I}, \mathrm{II}: \mathrm{III}, \mathrm{IV})$ & $40: 40$ & $24: 16$ & $16: 24$ & 0.1170 \\
\hline PNI $(\leq 45:>45)$ & $49: 32$ & $21: 19$ & $28: 13$ & 0.1763 \\
\hline $\operatorname{NLR}(\leq 2.5:>2.5)$ & $40: 41$ & $22: 18$ & $18: 23$ & 0.3771 \\
\hline $\operatorname{PLR}(\leq 150:>150)$ & $39: 42$ & $22: 18$ & $17: 24$ & 0.2692 \\
\hline Postoperative maximum number of neutrophils ( $\leq 9807:>9807 / \mu 1)$ & $41: 40$ & $18: 22$ & $23: 18$ & 0.3771 \\
\hline Postoperative maximum number of lymphocytes $(\leq 1513:>1513 / \mu 1)$ & $41: 40$ & $19: 21$ & $22: 19$ & 0.6590 \\
\hline Postoperative maximum number of monocytes $(\leq 815:>815 / \mu 1)$ & $41: 40$ & $18: 22$ & $23: 18$ & 0.3771 \\
\hline Postoperative maximum number of basophils $(\leq 58:>58 / \mu 1)$ & $41: 40$ & $18: 22$ & $23: 18$ & 0.3771 \\
\hline Postoperative peak value of CRP ( $\leq 9.7:>9.7 \mathrm{mg} / \mathrm{dl})$ & $41: 40$ & $19: 21$ & $22: 19$ & 0.6590 \\
\hline
\end{tabular}

OS, overall survival; CCA, cholangiocarcinoma; tub1, well differentiated type; tub2, moderately differentiated type; PNI, prognostic nutritional index; NLR, neutrophil-to-lymphocyte ratio; PLR, platelet-to-lymphocyte ratio; CRP, C-reactive protein; major hepatectomy: >3 segments;

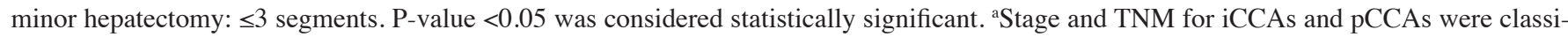
fied by the 6th edition of the general rules for the clinical and pathological study of primary liver cancer and the 6th edition of general rules for clinical and pathological studies on cancer of the biliary tract, respectively.

were associated with the SAR, we investigated the univariate analysis for the SAR including other factors (Table SI). The univariate analysis detected several risk factors for the SAR in CCA patients receiving hepatectomy, including the postoperative maximum number of leukocytes ( $\mathrm{PNL}, \mathrm{P}=0.0076$ ). Among leukocytes, PNN and PNE were risk factors for the SAR (PNN/PNE, P=0.0039/0.0008, Table SII).

Regarding to the treatment after recurrence, there were 16 patients without treatments after recurrence and 44 patients treated by mainly chemotherapy. Evaluating with PNN and PNE, there was no significant difference among high/low-PNN group in the presence of treatment after recurrence (respectively, 64.3\%/81.3\%, $\mathrm{P}=0.1569)$, and among high/low-PNE group (respectively, 83.9\%/62.1\%, $\mathrm{P}=0.0807$ ). Whereas, we investigated clinical impact of the site of recurrence on SAR. There were 62 recurrence cases; 29 cases in the liver, 8 cases at the peritoneal dissemination, 7 cases in the lymph node, and 7 cases in other sites. There was no significant association with the site of recurrence among between high and low-PNN/PNE groups (respectively, $\mathrm{P}=0.7418 / \mathrm{P}=0.7311$ ).

\section{Discussion}

We revealed that the postoperative peak number of leukocytes for CCA patients after hepatectomy was associated with the long-term prognosis, especially with regard to the OS and SAR, and the PNN and PNE were dominant components in the increase in leukocyte numbers. We also investigated the prognosis for patients of eCCA who underwent surgery without hepatectomy. There was no significant difference in OS, DFS and SAR with PNN (OS/DFS/SAR, $\mathrm{P}=0.6514 / 0.6630 / 0.6817)$ and PNE (OS/DFS/SAR, P=0.5980/05254/0.6372) (Fig. S1). 
Because the clinical impact of postoperative leukocytes was observed in only CCA patients with hepatectomy, we considered that the immune response might be different between patients with hepatectomy and patients without hepatectomy. Thus, we focused on the immune response for CCA patients after hepatectomy in this study.

The immune response following liver resection has been shown to influence various immune functions represented by several cytokines and growth factors (21). As we previously reported, these reactions and changes in levels of cytokines/growth factors facilitate CCA progression (22-26). Thus, we assumed that the postoperative peak number of leukocytes/CRP would be good surrogate markers and useful prediction tools for the OS.

The postoperative level of CRP, which has been described as a postoperative risk marker in other tumors $(18,27)$ was not associated with the prognosis in CCA. In contrast, an increased peak number of leukocytes was associated with a poorer OS, showing some degree of contradiction between these two findings. We therefore considered that the liver may not fully react and produce CRP sufficiently after hepatectomy in some cases, as CRP is produced in mainly by the liver.

The PNN was a significant risk factor of the OS. Historically, neutrophils were considered to have no effect on chronic or progressive diseases, such as cancer, due to the relatively short survival of such patients. Recently, however, several studies have revealed that the presence of neutrophils in tumors is associated with a poor prognosis in some tumors, such as bronchoalveolar carcinoma, melanoma, renal carcinoma and head and neck squamous cell carcinoma (28-32). Regarding a tumor-promoting role, neutrophils in inflammatory response product cytokines, proteases, and reactive oxygen species (ROS) (33). Interleukin-6 (IL-6) in particular is a marker of inflammation and the neuroendocrine stress response after surgery for primary biliary cancer and is a dominant inflammatory cytokine in the postoperative period $(34,35)$. We previously revealed that IL-6 was associated with malignant features in CCA $(23,25)$. The IL-6 expression was found to induce chemoresistance in CCA cells through epithelial-mesenchymal transition (EMT) (23). Thus, neutrophils might be induced in the acute inflammation period after hepatectomy by cytokines, including IL-6, and CCA exacerbated by IL-6 exposure carries a poor prognosis for patients.

In contrast to findings concerning neutrophils, eosinophils have rarely shown any particular association with cancer. Albeit in only a few reports, eosinophils have been found to be associated with both favorable and unfavorable prognoses. Most reports on eosinophils in cancer have demonstrated the presence of eosinophil infiltration in tissues surrounding tumors, such as nasopharyngeal carcinoma, colorectal tumor, oral squamous cell carcinoma, pulmonary adenocarcinoma and laryngeal carcinoma (36-38). Increased eosinophil counts in patients with prostate cancer and metastatic colon cancers have been shown to be associated with a prolonged survival $(39,40)$. Recently, there have been reports that the short-term administration of IL-33 facilitates the development of a murine genetic model of CCA (22). However, the clinical role of IL-33 in CCA has not been investigated. IL-33, a member of the IL-1 family, has been shown to be a crucial costimulator of the adaptive immune response, exerting effects on antiviral $\mathrm{CD}^{+}$cytotoxic $\mathrm{T}$ lymphocytes, $\mathrm{CD}^{+} \mathrm{T}$ helper 1 cell reactions and immune regulation by regulatory $\mathrm{T}$ cells. We therefore initially assumed that an increase in eosinophils might be a surrogate marker of an increase in the expression of IL-33 and thus a risk factor of the prognosis of CCA patients. However, we observed the opposite results. Although these findings seemed to conflict with our hypothesis, several reports have shown that IL-33 does not increase the number of eosinophils in all cases. Tjota and Stolarski suggested that IL-33 was involved in both increases and decreases in the number of eosinophils. In contrast, Dyer et al determined that IL-33 antagonized IL-5-dependent eosinophilopoiesis (41-43). Those previous results may partially explain the findings in the present study.

After getting the result, we reanalyzed the prognosis dividing CCA patients into iCCA patients and eCCA patients. Particularly, OS and SAR for the high-PNN group in iCCA patients seemed to be inferior comparing to the low-PNN group in iCCA patients, although there was no significant different, maybe because of the small number (OS/SAR, $\mathrm{P}=0.1124 / 0.1629$ ) (Fig. S2). We need to accumulate more cases for further investigation.

In conclusion, the postoperative peak number of leukocytes after hepatectomy was significantly associated with the long-term prognosis in patients with CCA. Although studies in a larger group are still needed, changes in the numbers of leukocytes after hepatectomy may be a marker on treatment for CCA.

\section{Acknowledgements}

Not applicable.

\section{Funding}

No funding was received.

\section{Availability of data and materials}

The datasets used and/or analyzed during the current study are available from the corresponding author on reasonable request.

\section{Authors' contributions}

GS made substantial contributions to acquisition of data and drafting the manuscript. DY and HE made substantial contributions to conception, design, revising the manuscript. HE, YI, HA, TA, TN and KG made contribution to acquisition of data and revising manuscript. SK, YT and MT made substantial contributions to analysis and interpretation of data. YD and MM revising it critically for important intellectual content, given final approval of the version. And All authors read and approved the final manuscript.

\section{Ethics approval and consent to participate}

Written informed consent was obtained from all participants. This retrospective study protocol was approved by the 
institutional reviewer board of the Osaka University Graduate School of Medicine (Suita, Japan) (no. 18261).

\section{Patient consent for publication}

Not applicable.

\section{Competing interests}

The authors declare that they have no competing interests.

\section{References}

1. Anderson CD, Pinson CW, Berlin J and Chari RS: Diagnosis and treatment of cholangiocarcinoma. Oncologist 9: 43-57, 2004.

2. Howlader N, Noone AM and Krapcho M: SEER Cancer Statistics Review 1975-2008. National Cancer Institute, Bethesda, MD, 2018

3. Toyoda M, Ajiki T, Fujiwara Y, Nagano H, Kobayashi S, Sakai D, Hatano E, Kanai M, Nakamori S, Miyamoto A, et al: Phase I study of adjuvant chemotherapy with gemcitabine plus cisplatin in patients with biliary tract cancer undergoing curative resection without major hepatectomy (KHBO1004). Cancer Chemother Pharmacol 73: 1295-1301, 2014.

4. Colvin H, Mizushima T, Eguchi H, Takiguchi S, Doki Y and Mori M: Gastroenterological surgery in Japan: The past, the present and the future. Ann Gastroenterol Surg 1: 5-10, 2017.

5. Miyakawa S, Ishihara S, Horiguchi A, Takada T, Miyazaki M and Nagakawa T: Biliary tract cancer treatment: 5,584 results from the Biliary Tract Cancer Statistics Registry from 1998 to 2004 in Japan. J Hepatobiliary Pancreat Surg 16: 1-7, 2009

6. Wellner UF, Shen Y, Keck T, Jin W and Xu Z: The survival outcome and prognostic factors for distal cholangiocarcinoma following surgical resection: A meta-analysis for the 5-year survival. Surg Today 47: 271-279, 2017.

7. Higuchi R, Ota T, Yazawa T, Kajiyama H, Araida T, Furukawa T, Yoshikawa T, Takasaki K and Yamamoto M: Improved surgical outcomes for hilar cholangiocarcinoma: Changes in surgical procedures and related outcomes based on 40 years of experience at a single institution. Surg Today 46: 74-83, 2016.

8. Kobayashi S, Miyamoto A, Shimizu J, Kashiwazaki M, Takeda Y, Ueshima S, Kim Y, Kitagawa T, Dono K, Mori M, et al: Comparison of 4-weekly vs 3-weekly gemcitabine as adjuvant chemotherapy following curative resection for biliary tract cancer: A prospective randomized controlled trial. J Cancer Ther 02: 703-709, 2011.

9. Kobayashi S, Nagano H, Sakai D, Eguchi H, Hatano E, Kanai M, Seo S, Taura K, Fujiwara Y, Ajiki T, et al: Phase I study of adjuvant gemcitabine or $\mathrm{S}-1$ in patients with biliary tract cancers undergoing major hepatectomy: KHBO1003 study. Cancer Chemother Pharmacol 74: 699-709, 2014.

10. Mizuno T, Ebata T, Yokoyama Y, Igami T, Sugawara G, Yamaguchi $\mathrm{J}$ and Nagino M: Adjuvant gemcitabine monotherapy for resectable perihilar cholangiocarcinoma with lymph node involvement: A propensity score matching analysis. Surg Today 47: 182-192, 2017.

11. Chen Q, Dai Z, Yin D, Yang LX, Wang Z, Xiao YS, Fan J and Zhou J: Negative impact of preoperative platelet-lymphocyte ratio on outcome after hepatic resection for intrahepatic cholangiocarcinoma. Medicine (Baltimore) 94: e574, 2015.

12. Gomez D, Morris-Stiff G, Toogood GJ, Lodge JP and Prasad KR: Impact of systemic inflammation on outcome following resection for intrahepatic cholangiocarcinoma. J Surg Oncol 97: 513-518, 2008.

13. Zhang C, Wang H, Ning Z, Xu L, Zhuang L, Wang P and Meng Z: Prognostic nutritional index serves as a predictive marker of survival and associates with systemic inflammatory response in metastatic intrahepatic cholangiocarcinoma. OncoTargets Ther 9: 6417-6423, 2016.

14. Tibau A, Ennis M and Goodwin PJ: Post-surgical highly sensitive C-reactive protein and prognosis in early-stage breast cancer. Breast Cancer Res Treat 141: 485-493, 2013.

15. Saito T, Kurokawa Y, Miyazaki Y, Makino T, Takahashi T, Yamasaki M, Nakajima K, Takiguchi S, Mori M and Doki Y: Which is a more reliable indicator of survival after gastric cancer surgery: Postoperative complication occurrence or C-reactive protein elevation? J Surg Oncol 112: 894-899, 2015.
16. Lu Y, Huang S, Li P, Chen B, Liu W, Chen Z and Yin F: Prognostic evaluation of preoperative serum $\mathrm{C}$-reactive protein concentration in patients with epithelial ovarian cancer. Exp Ther Med 9: 2003-2007, 2015.

17. Fujiwara Y, Shiba H, Furukawa K, Iida T, Sakamoto T, Gocho T, Wakiyama S, Hirohara S, Ishida Y, Misawa T, et al: Perioperative change in white blood cell count predicts outcome of hepatic resection for hepatocellular carcinoma. J Hepatobiliary Pancreat Sci 17: 892-897, 2010

18. Shiba H, Furukawa K, Fujiwara Y, Futagawa Y, Haruki K, Wakiyama S, Ishida Y, Misawa T and Yanaga K: Postoperative peak serum C-reactive protein predicts outcome of hepatic resection for hepatocellular carcinoma. Anticancer Res 33: 705-709, 2013.

19. Japanese Society of Hepato-Biliary-Pancreatic Surgery: General Rules for Clinical and Pathological Studies on Cancer of the Biliary Tract. 6th edition. Kanehara and Co., Ltd., Tokyo, 2013.

20. Liver Cancer Study Group of Japan: General Rules for the Clinical and Pathological Study of Primary Liver Cancer. 6th edition. Kanehara and Co., Ltd., Tokyo, 2015.

21. Ando T, Ito H, Kanbe A, Hara A and Seishima M: Deficiency of NALP3 Signaling Impairs Liver Regeneration After Partial Hepatectomy. Inflammation 40: 1717-1725, 2017.

22. Yamada D, Rizvi S, Razumilava N, Bronk SF, Davila JI, Champion MD, Borad MJ, Bezerra JA, Chen X and Gores GJ: IL-33 facilitates oncogene-induced cholangiocarcinoma in mice by an interleukin-6-sensitive mechanism. Hepatology 61: $1627-1642,2015$

23. Yamada D, Kobayashi S, Wada H, Kawamoto K, Marubashi S, Eguchi H, Ishii H, Nagano H, Doki Y and Mori M: Role of crosstalk between interleukin-6 and transforming growth factor-beta 1 in epithelial-mesenchymal transition and chemoresistance in biliary tract cancer. Eur J Cancer 49: 1725-1740, 2013.

24. Sakamoto T, Kobayashi S, Yamada D, Nagano H, Tomokuni A, Tomimaru Y, Noda T, Gotoh K, Asaoka T, Wada H, et al: A histone deacetylase inhibitor suppresses epithelial-mesenchymal transition and attenuates chemoresistance in biliary tract cancer. PLoS One 11: e0145985, 2016.

25. Kobayashi S, Werneburg NW, Bronk SF, Kaufmann SH and Gores GJ: Interleukin-6 contributes to Mcl-1 up-regulation and TRAIL resistance via an Akt-signaling pathway in cholangiocarcinoma cells. Gastroenterology 128: 2054-2065, 2005.

26. Yamada D, Kobayashi S, Yamamoto H, Tomimaru Y, Noda T, Uemura M, Wada H, Marubashi S, Eguchi H, Tanemura M, et al: Role of the hypoxia-related gene, JMJD1A, in hepatocellular carcinoma: Clinical impact on recurrence after hepatic resection. Ann Surg Oncol 19 (Suppl 3): S355-S364, 2012.

27. Ibuki Y, Hamai Y, Hihara J, Emi M, Taomoto J, Furukawa T, Yamakita I, Kurokawa T and Okada M: Role of postoperative C-reactive protein levels in predicting prognosis After surgical treatment of esophageal cancer. World J Surg 41: 1558-1565, 2017.

28. Trellakis S, Bruderek K, Dumitru CA, Gholaman H, Gu X, Bankfalvi A, Scherag A, Hütte J, Dominas N, Lehnerdt GF, et al: Polymorphonuclear granulocytes in human head and neck cancer: Enhanced inflammatory activity, modulation by cancer cells and expansion in advanced disease. Int J Cancer 129: 2183-2193, 2011

29. Schmidt H, Bastholt L, Geertsen P, Christensen IJ, Larsen S, Gehl J and von der Maase H: Elevated neutrophil and monocyte counts in peripheral blood are associated with poor survival in patients with metastatic melanoma: A prognostic model. Br J Cancer 93: 273-278, 2005

30. Uribe-Querol E and Rosales C: Neutrophils in cancer: Two sides of the same coin. J Immunol Res 2015: 983698, 2015.

31. Wislez M, Rabbe N, Marchal J, Milleron B, Crestani B, Mayaud C, Antoine M, Soler P and Cadranel J: Hepatocyte growth factor production by neutrophils infiltrating bronchioloalveolar subtype pulmonary adenocarcinoma: Role in tumor progression and death. Cancer Res 63: 1405-1412, 2003.

32. Jensen HK, Donskov F, Marcussen N, Nordsmark M, Lundbeck F and von der Maase H: Presence of intratumoral neutrophils is an independent prognostic factor in localized renal cell carcinoma. J Clin Oncol 27: 4709-4717, 2009.

33. Grivennikov SI, Greten FR and Karin M: Immunity, inflammation, and cancer. Cell 140: 883-899, 2010.

34. Cata JP, Velasquez JF, Ramirez MF, Vauthey JN, Gottumukkala V, Conrad C, Kim BJ and Aloia T: Inflammation and pro-resolution inflammation after hepatobiliary surgery. World J Surg Oncol 15: $152,2017$. 
35. Alazawi W, Pirmadjid N, Lahiri R and Bhattacharya S: Inflammatory and immune responses to surgery and their clinical impact. Ann Surg 264: 73-80, 2016.

36. Fujii M, Yamashita T, Ishiguro R, Tashiro M and Kameyama K: Significance of epidermal growth factor receptor and tumor associated tissue eosinophilia in the prognosis of patients with nasopharyngeal carcinoma. Auris Nasus Larynx 29: 175-181, 2002.

37. Nielsen HJ, Hansen U, Christensen IJ, Reimert CM, Bru N and Moesgaard F: Independent prognostic value of eosinophil and mast cell infiltration in colorectal cancer tissue. J Pathol 189: 487-495, 1999.

38. Jain M, Kasetty S, Sudheendra US, Tijare M, Khan S and Desai A: Assessment of tissue eosinophilia as a prognosticator in oral epithelial dysplasia and oral squamous cell carcinoma-an image analysis study. Pathol Res Int 2014: 507512, 2014.

39. McNeel DG, Gardner TA, Higano CS, Kantoff PW, Small EJ, Wener MH, Sims RB, DeVries T, Sheikh NA and Dreicer R: A transient increase in eosinophils is associated with prolonged survival in men with metastatic castration-resistant prostate cancer who receive sipuleucel-T. Cancer Immunol Res 2: 988-999, 2014.
40. Yalcin AD, Kargi A and Gumuslu S: Blood eosinophil and platelet levels, proteomics patterns of trail and CXCL8 correlated with survival in bevacizumab treated metastatic colon cancers. Clin Lab 60: 339-340, 2014.

41. Tjota MY, Williams JW, Lu T, Clay BS, Byrd T, Hrusch CL, Decker DC, de Araujo CA, Bryce PJ and Sperling AI: IL-33-dependent induction of allergic lung inflammation by $\mathrm{Fc} \gamma \mathrm{RIII}$ signaling. J Clin Invest 123: 2287-2297, 2013.

42. Stolarski B, Kurowska-Stolarska M, Kewin P, Xu D and Liew FY: IL-33 exacerbates eosinophil-mediated airway inflammation. J Immunol 185: 3472-3480, 2010.

43. Dyer KD, Percopo CM and Rosenberg HF: IL-33 promotes eosinophilia in vivo and antagonizes IL-5-dependent eosinophil hematopoiesis ex vivo. Immunol Lett 150: 41-47, 2013. 